\title{
A concept for the modernization of underground mining master maps based on the enrichment of data definitions and spatial database technology
}

\author{
Artur Krawczyk ${ }^{1, *}$ \\ ${ }^{1}$ AGH University of Science and Technology, Faculty of Mining Surveying \& Environmental Engineering; Department of Mine Areas \\ Protection, Geoinformatics and Mine Surveying, al. Mickiewicza 30, 30-059 Cracow, Poland
}

\begin{abstract}
In this article, topics regarding the technical and legal aspects of creating digital underground mining maps are described. Currently used technologies and solutions for creating, storing and making digital maps accessible are described in the context of the Polish mining industry. Also, some problems with the use of these technologies are identified and described. One of the identified problems is the need to expand the range of mining map data provided by survey departments to other mining departments, such as ventilation maintenance or geological maintenance. Three solutions are proposed and analyzed, and one is chosen for further analysis. The analysis concerns data storage and making survey data accessible not only from paper documentation, but also directly from computer systems. Based on enrichment data, new processing procedures are proposed for a new way of presenting information that allows the preparation of new cartographic representations (symbols) of data with regard to users' needs.
\end{abstract}

\section{Introduction}

The first use of databases in the underground mining industry in Poland dates back to the 1980s. At that time, they were mostly used in financial management and bookkeeping tasks. It was not until the 90 s that CAD (Computer Aided Design) was implemented in the industry for the purpose of creating digital mining maps. This involved implementing software not only for mine scheduling and management of geological resources, but also in various other mining departments. Since this process was not sufficiently controlled, some issues with sharing spatial data stored in binary CAD files (AutoCAD, MicroStation) arose.

These problems can be divided into two categories: 1) parallel sharing and viewing of mining map files and 2) limitations in controlling and managing all aspects of geological and survey records. The problem with the "parallel sharing" of data by many users comes from the design of CAD technology. Vector data stored in binary files is not designed for simultaneous use by many users. Map data files have to be updated to the current state of excavation at the end of each annual quarter. The number of employees needed for this update could exceed the number of installed copies of CAD software as mining companies usually buy as few licenses as possible due to the expense. This causes problems with accessing the data. The data management limitations are caused by the complex way in which survey and geological data are organized. This includes handmade sketches on paper and the results of calculations done in various survey programs which are printed and saved in binders stamped and signed by an authorized employee. During the map creation process in $\mathrm{CAD}$, the vector graphic system loses attribute data, which remain only in paper form. The scope of data on mining maps was defined in the 70s and is no longer sufficient. A lot of data has to be interpreted from original two-dimensional maps in order to extrapolate spatial information about the third dimension [1].

\section{Some details on underground mining maps}

The definition of an underground mining map states that it should present the current mining situation and geological structure. It also should include the condition of the terrain surface (with buildings) within the borders of the mining area. In order to fulfill these conditions, each mine needs to have surveying and geological departments which prepare and review master maps and special (detailed) maps. In Poland master maps are usually created at a scale of 1:2000, while review maps use a scale of 1:5000 or 1:10 000. Master and review maps detail the actual conditions in the mine. In turn, special maps show conditions in a different color, or simplifies them in order to enhance the primary purpose of the map.

\footnotetext{
*Corresponding author: artkraw@agh.edu.pl
} 


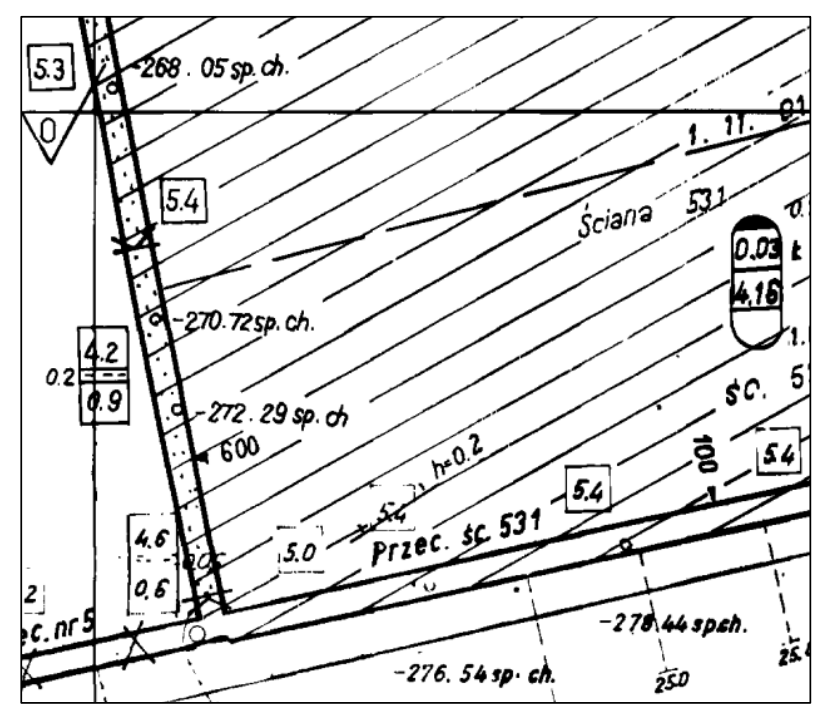

Fig. 1. A section of an underground mining map (1:5000).

The creation of underground mining maps consists of a few stages. Firstly, a survey is done and the results are written accordingly in survey and geological books. All calculations are done in appropriate software and stored. The third and most important part is drawing the map. This process can be done in the traditional manner by hand-made drawings on paper maps glued to an aluminum plate, or it can be done in CAD software enhanced by dedicated plugins.

It is important to emphasize that the visual part of a map is a highly sophisticated and complicated product; therefore, special software plugins for drawing must be used.

The regulations regarding the described maps are given in Geology and Mining Law [2] Article 116, which states that it is necessary to have survey and geological documentation that should be updated in relation to the excavation process. This documentation includes:

1. survey reports,

2. calculation reports (usually provided by survey software),

3. cartographic documentation of the current geological and mining situation, including the surface condition (and buildings) within the borders of the mining area.

Article 116 specifies that only qualified surveyors and geologists are allowed to provide survey and geological information and that they are obligated to update documentation with appropriate survey data and calculations. The "Geological and Mining law" [2] regulation in Article 116 refers to the Regulation of the Ministry of Environment dated 22 December 2011, regarding survey and geological documentation. Paragraph 7 point 2 describes the conditions that cartographic digital documentation must fulfill. Digital cartographic documentation can be done if:

1. it is properly secured,

2. all updates are stored and recorded so that older versions of files can be restored,

3. the mining company can plot the digital document at any time. If this is not done, the mining company must store a plot of an updated version of the documentation. if:

On this basis, digital maps can be implemented only

- Original maps are stored in servers managed and located in survey departments.

- Digital copies of the maps are stored in two places: one outside the mine (e.g. in the central office) and the other on the server in the mine survey department.

- A paper map repository stores paper plots of digitally updated maps instead of manually updated paper maps.

- The plots are done every 3 months; only updated sections are plotted.

- Sections not updated need to be plotted every year.

This last condition relates to the physical properties of paper, which can deteriorate with time. In uncontrolled conditions, maps lose the cartographic properties within 6 months. In air-conditioned conditions, printed maps can remain usable for up to a year. Based on this regulation, it is possible to stop creating and manually updating paper on aluminum plate maps by converting these maps to digital versions.

All these regulations mean that the primary task of the survey department is to obtain a product in accordance with the legal regulations applying to the storage.

The main problem with new CAD solutions for creating and plotting maps is that attribute (textual) information is still not attached to the graphic elements.

The basic information provided by the survey department is the geometry of sidewalls measured by survey mining staff. The xyz geodetic coordinates of these points are then calculated and the points are mapped and drawn as continuous lines, but information about the third coordinate $(z)$ is not stored [3]. The original maps are made at a scale of 1:2000 or 1:1000 (depending on the type of mine). When maps are scaled to 1:5000 or $1: 10000$, they are subjected to cartographic editing that results in descriptions being moved or elevation points deleted due to the density of the information. On the master map, two or three points per $100 \mathrm{~m}$ of excavation are drawn as points with ordinate information (the $\mathrm{z}$ coordinate value is added as text).

After master map generalization to convert to a scale of $1: 10000$ or $1: 5000$, the number of points with a known $\mathrm{z}$ value decreases. On the other hand, elevation information is very important for the other departments because it allows the specification of parameters such as the direction of the excavation slope or the slope value. This parameter is also important for underground transport and ventilation purposes. In turn, the height of the excavation is important for geologists and miners.

The ideal situation would be if a survey department could provide all of this kind of data to other departments for them to use freely. This however, cannot be achieved without changes in current data processing.

\section{Proposed solutions for reducing limitations on managing survey data for other mine maintenance departments}

Paper reports are produced during the creation of surveys and geological documentation. They include handmade survey sketches, miner's sketches and other 
documentation. The aim of modernization is to convert this paper-based data to a digital format. At the time of this article, no Polish mines have a digital system for storing this kind of data.

The first modernization concept is the "flat solution", which involves scanning sketches and storing them in pdf format with geo-reference data added to the coordinates system used in each mine. The sketches should then be equipped with the results of calculations obtained from specialized survey programs (also as pdf files). The created set of pdf files with measurement information can be referenced by linking to the vector geometry of the sidewalls line drawn on the map. This solution can be used in CAD and GIS environments and improves access to the raw data; however, data in a pdf file is not very convenient for other mining departments.

The second most advanced modernization concept is the "full numeric approach". This idea is based on the modernization of survey data acquisition methods (first stage of map creation) during measurement, such as the use of electronic devices like laptops or tablets instead of paper. Numeric and geometry data from measurements can be stored and transferred from devices directly into numeric spatial database fields such as SDO_Geometry or Well-Known Binary, both of which are commonly used in open source software.

However, using electronic devices underground can cause problems with the flammable methane that is often present in mines. All electronic devices have to be constructed and tested for safety under these conditions. So far, only expensive geodetic instruments have been constructed and certified for use as such.

The least advanced solution is based on the idea of "enriching the map definition" beyond the legal regulations. The solution begins from extending the number of data sets measured during underground surveys. New data sets should be separated from other legal data sets, but they can still be used by other departments. Also, cartographic presentation can be changed depending on the mine maintenance department's needs. The same information should be prepared in a different form for appropriate maintenance departments. Cartographic representation of new data sets leads to the next problem of representation of these data on maps in multi-resolution environments. This involves problems with creating generalization rules when concerting to other scales. These considerations are similar to the proposed solution to problems with generalization in topography maps [4].

\section{Modernization technology for survey coordinate data based on enriched map definitions}

During map creation by mining surveyors, only a few elevation points inside the excavation are placed on the map, Fig. 2a. The scale of this representation is based on the scale of master maps used in a particular mine. The number of measurements taken during a survey is much higher than is placed on the map. This is done according to the cartographic rules for the creation of mining maps.
The first concept for the "enriched map definition" is based on increasing the amount of data placed on the map. Fig. $2 b$ shows an increased number of elevation points.

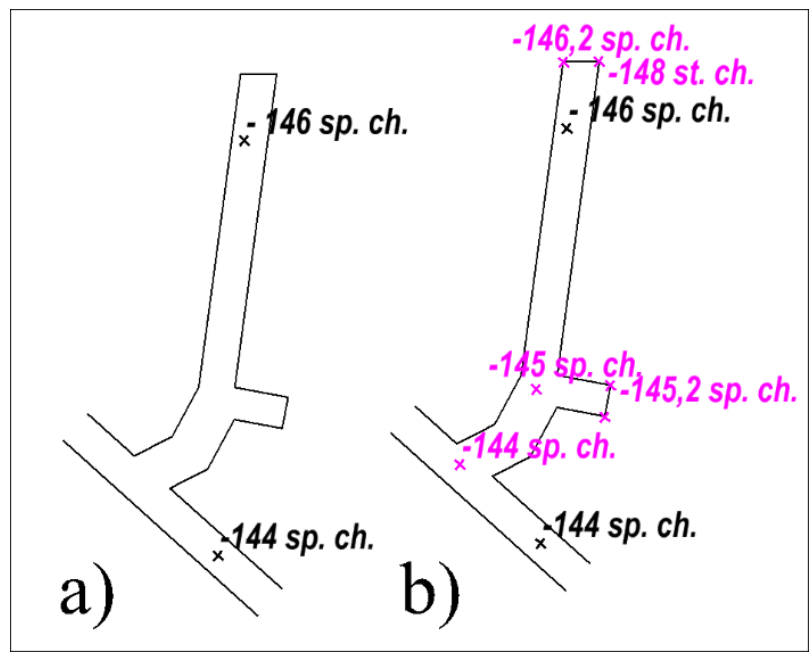

Fig. 2. Geometric representation for a survey: a) typical representation of sidewalls and elevation pegs on the master map; b) proposed additional set of data as "enriched map definition".

These added points are selected according to some rules: 1) for the modeling of spatial mining data, it is very useful to have elevation points on excavation crossings, 2) for geology and mining planning, it is useful to have data about the height of the mining face, 3) for transportation purposes, it is useful to have more information about the direction and value of the excavation slope.

New elevation data presented in Fig. 2b. should be placed in separate data sets with new data attributes, such as the type of data source enrichment. There should not be a cartographic version of this additional data because there is no intention of using it when plotting maps. Elevation data is used to create new information described in the second part of the concept.

The second part of the modernization concept is the creation of new information and cartographic representations for use by other departments:

1) For transportation and ventilation, the key information on the map is the slope of the excavation. These data are needed for planning and servicing transportation systems. The ventilation dept. provides information on the placement of ventilators, ventilation dams, and the direction of the air flow in a mine. The new slope representation is based on the enriched survey data set. The example slope value is placed below the excavation. Units are given in promille \%o (one-tenth of a percent), or as a percentage. Calculating a slope value requires at least two elevation values from pegs. The first peg must be located at the beginning of the excavation; the second must be located at the end of the excavation. Both pegs must be located on the floor of the excavation (in Polish, pegs labeled "sp. ch." are on the excavation floor). The cartography symbol for the slope is presented in Fig. 3 as an arrow with the value of the slope. 
2) For the geology department and the mine casing design department, the key information about the excavation is the floor slope and the height of excavation. For geological reasons, the height is important in order to control the data included on the map. The map contains detailed information about the thickness of geological layers identified in this excavation in meters, but there is no information about the height of the excavation. The total thickness of the geological layers in the excavation should be equal to its height. The height of the excavation is also important for the casing design for new mining works. Before a project starts, the planning stage needs data for evaluation and information about the conditions for the planned mining work. A typical way of obtaining this information is to calculate the height from the floor pegs and the roof pegs (labeled "st. ch."). The problem with this calculation is that the pegs on the roof are usually placed in different locations than the floor pegs, sometimes with remarkably long distances between them. In ideal conditions for calculating, the planar positions (xy) of those pegs should be the same. In the new concept, data filtering provides proper data to obtain the height of the excavation. In Fig. 3, new cartographic symbols are presented for symbolizing the height of the excavation; these are marked as "w. ch." and show the height in meters.

3) For spatial underground modeling, the key information is the axis of the existing excavation, which is a source for planning new mining works.

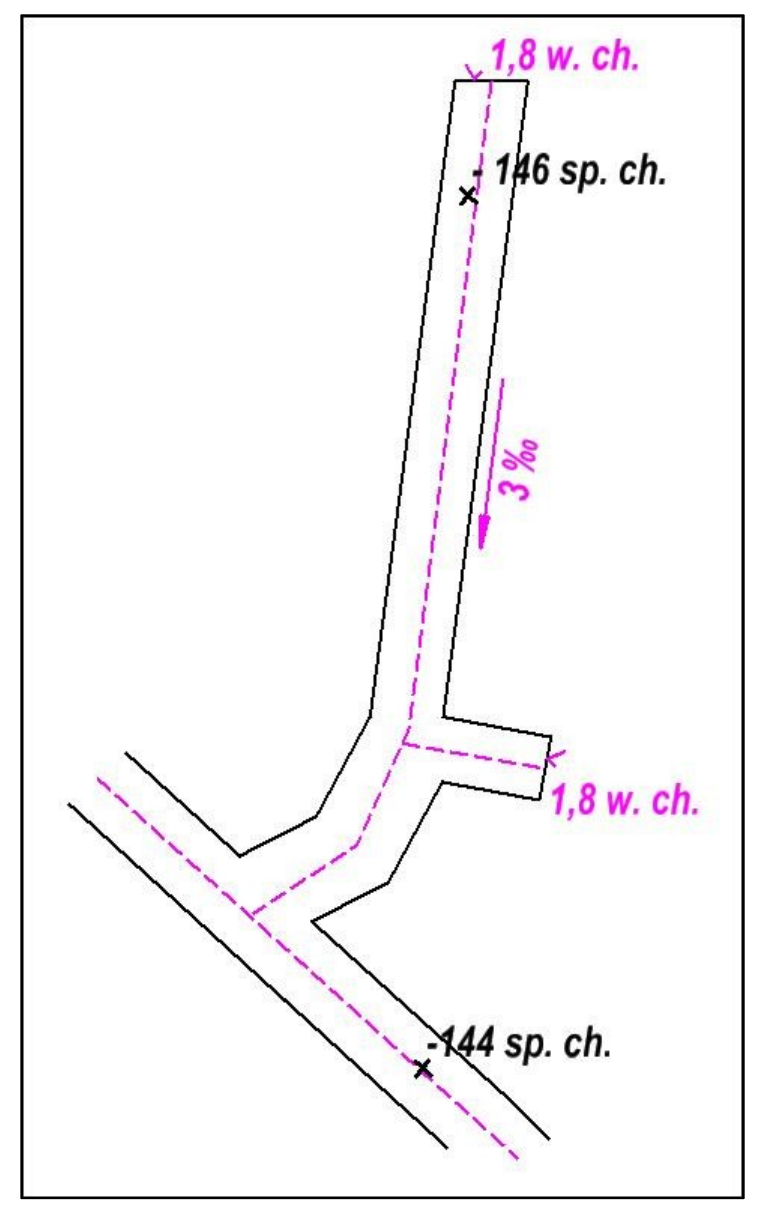

Fig. 3. Enriched cartographic symbols for mining master map.
The first idea of the "enriched map definition" concept indicates that the system should also gather data from the survey for estimation of the axes.

The geometry of the excavation axis shown on the map is a complicated problem in mining information systems. Poniewiera [5] described this problem and implemented a software tool for supporting manual drawing of excavation axes. In the GeoLISP solution, the surveyor manually draws a line between the sidewalls of the excavation. This method works well at a small scale (one person working on around a dozen mining map sheets), but at a large scale (many people, a lot of mining map sheets) the quality of work deteriorates. The primary issue with manual digitizing is mistakes made during hand drawing of the axis when it intersects the line of sidewalls. To avoid this situation, the enriched data model uses more pegs situated in the middle of the excavation floor to prepare a ready-to-use data set for connecting points manually or semi-automatically. The excavation axes play several important roles in spatial data modeling for mining works [6], numeric data modeling of seams [7], and also for visualization and animation [8].

\section{Concept of mining base map stored in a spatial database}

So far in mining in Poland, spatial database technology has not been used to store and manage legal mining maps. However, [9] in 2013 LW Bogdanka S.A. (a mine in Poland) started planning and implementing a new system called Mining Infrastructure Object Maps (MIOM) that is based on spatial database technology. This system was created for control over assets in underground excavations. It collects information about mining machinery and equipment such as catalog identification number, technical description and location. Spatial data is stored in an Oracle Database, where it is edited by Bentley Map GIS class software. This system was created in longterm cooperation with the LW Bogdanka S.A. Coal Mine and IGSMiE PAN and used for the inventory process of underground infrastructure. In 2010 in the Bogdanka mine, PRGW Company implemented a CAD-based system for mining master map production called SoftMine MapaKWK. This shows that two spatial data systems already exist. Where a master mining map is used as a reference map for a Mining Infrastructure Object Map [10], the cooperation between these systems is possible only because both systems use the same graphic platform: Bentley MicroStation.

This example shows that a spatial Oracle database is well-suited to storing any kind of spatial data [11], including data defined for master mining maps. This system can also store scanned miner's sketches and data from survey instruments. Based on this, the database can also store all input data and result data from survey calculations, therefore this data can be secured and used by miners from other departments. Relational databases provide tools for data sharing and editing in a multi-user environment. Edited data can be viewed but not edited by unauthorized users. Geometry stored in spatial tables can be edited by GIS class software, thus allowing the creation 
of a master mining map without the use of CAD software. An additional advantage of spatial data bases is high level data interoperation based on markup languages [12]. The main problem with this solution is the separation of geometry data styling, which is not a common technique in the mining industry.

\section{Conclusion}

The most important objective is to connect two trends into one solution for all mine maintenance departments. The first problem is that the old definition of master mining maps is obsolete and needs to be improved. The second problem is the modernization of technology to allow the transfer of data from CAD systems (editing and storing) to spatial databases. These two trends are interdependent. New technology offers more ways of gathering and analyzing spatial data, and this is exactly what users need.

Of course, the concept proposed in this article needs further analysis in order to determine the details of implementation. It is also important to do further tests on a bigger data set. However, even this generalized concept provides an alternative to the currently used methods of editing and storing surveyed data. Databases represent an excellent tool for complying with the new laws that are pending in the mining industry.

The article was done in the framework of the "Badania Statutowe" grant of the Department of the Protection of Mining Areas, Geoinformation and Mine Surveying, AGH-UST no. 11.11.150.195

\section{References}

1. L. Wu, Z. Yin, Y. Zhong, Journal of China Coal Society 28 (1), 1 (2003)

2. Geology and Mining Act (Journal of Law 2011/163/981, 2011)

3. J. Wang, B. Yang, M. Wu, Coal Science and Technology 32(5), (2004)

4. K. Kozioł, A. Krawczyk, M. Lupa, Beyond Databases, Architectures, and Structures, 435 (Springer International Publishing Switzerland, 2014)

5. W. Muras, M. Poniewiera, Zeszyty Naukowe Politechniki Śląskiej: Górnictwo 1752 (278), 313 (2007)

6. J. Maciaszek, R. Gawałkiewicz, I. Gawałkiewicz, Zeszyty Naukowe AGH: Geologia 36 (3), 331 (2010)

7. M. Poniewiera, Wiadomości Górnicze 61 (7-8), 458 (2010)

8. A. Krawczyk, VII Konf. Nauk.-Tech. Ochrona Środowiska na Terenach Górniczych, 127 (Katowice, Poland, June 2008)

9. S. Karlikowski, T. Parzniewski, D. Galica, Materiaty Konferencyjne SEP (Cracow, Poland, 2014)

10. T. Parzniewski, D. Galica, A. Dyczko, A. Krawczyk, Wiadomości Górnicze 67 (2), 115 (2016)

11. A. Godfrind, R. Kothuri, E. Beinat, Pro Oracle Spatial for Oracle Database $11 \mathrm{~g}$ (USA, 2007)

12. A. Krawczyk, Gospodarka Surowcami Mineralnymi 23 (4), 163 (2007) 